\title{
DESIGN AND FABRICATION OF AN IMPROVED MOTORIZED MAIZE SHELLER/THRESHING MACHINE
}

\author{
ADEWALE SEDARA ${ }^{1 *}$, EMMANUEL ODEDIRAN ${ }^{1}$, SETH MANUWA $^{1}$ \\ Department of Agricultural and Environmental Engineering, School of Engineering and \\ Engineering Technology, The Federal University of Technology, Akure, Nigeria
}

\begin{abstract}
One major essential operation in processing maize is shelling of maize. Maize shelling is one of the most important processing operations carried out in maize processing since it's among the widely consumed grains all over the world. Shelling bring out good quality of maize which not only prolong its useful life, but also increase the net profit farmers make from its mechanization. Component parts such as: frame, hopper, transmission shaft, cylinder with spikes and blower, concave with sieve, power source, pulley and bearings was designed and fabricated. It can be moved to where it's needed this would encourage farmers to shell their maize grains on the farm.
\end{abstract}

Keywords: maize grain, fabrication, shelling, motorized

\section{INTRODUCTION}

Maize (Zea mays L.) is among the main cereal grains grown worldwide in a wider range of environments because of its greater adaptability [1]. It is mainly for food source and now has become the most key raw material for animal feed [2]. Corn, popularly known as maize is a major staple food in the globe. It is the third largest cereal produced in the world [3]. It is, after wheat and rice cereal grain in the world. Nigeria is currently the tenth largest producer of maize in the world, and the largest maize producer in Africa [4]. It is estimated that seventy percent of farmers are smallholders accounting for 90 percent of total farm output [5].

Maize crop started as a subsistence crop in Nigeria and has gradually risen to a commercial crop on which many agro-based industries depend on as raw materials [6]. Maize is most productive in the middle and Northern belts of Nigeria, where sunshine is adequate and rainfall is moderate [7]. Maize shelling by hand and simple tools are difficult but also consumes time and energy. Even the existing motorized maize shellers, apart from the fact that they are costly to purchase or hire, they inflict great damage on maize grains during shelling process. The specific objectives of this research are to design and fabricate a motorized maize sheller.

Most sheller used abrasion between a rotating shelling disc and stationary concave compartment to achieve the stripping as reported by [8]. According to [9] the traditional method of maize dehusking was done manually with hand and shelling was done either by beating the dehusked cob of maize with sticks, finger, sickle, etc. This concept of a technology is more appropriate to the needs of developing countries and it's applied equally well to agricultural mechanization. This incurred the cost of transportation between farms to machine industry thereby increase the cost of production.

\footnotetext{
* Corresponding author, email: adewale.sedara@ gmail.com

(C) 2020 Alma Mater Publishing House
} 


\section{METHODOLOGY}

\subsection{Principles of operation}

The shelling is accomplished by the shearing by the rotating spikes mounted on the cylinder, which force out the grains from cobs holding them. Different grain crops and varieties have varying characteristics, which require different speeds for achieving the best result of shelling, therefore adjustment of cylinder speed and proper feeding of cobs is essential.

\subsection{Design consideration}

The following was considered for the machine.

\subsubsection{Stability}

This factor is a major focus point for improvement in the machine. This is the ability to remain stable and rigid during the shelling operation. The design prototype was put into consideration for balancing the weight of the entire machine. Also, the shelling force must be balance with the sheller.

\subsubsection{Sortability}

This is another factor in focus upon which improvement was made. It is the ability to separate maize grains into aggregates after shelling process inside the shelling chamber. The whole maize seeds or kernels flow out through the shelled grains outlet while the maize comb or residual shafts simultaneously flow out through another outlet, thereby sorting the aggregates separately.

\subsubsection{Transportability}

The ability to be moved is a very important factor, since farmer may have farms in different locations. Also, if it is used for commercial purpose, it would be easy to transport from farm to farm. The design therefore gives room for transportability.

\subsubsection{Durability}

The choice of materials for the machine parts are such that will last longer before replacement of parts begins to be demanded as a result stress and wears undergo from time to time.

\subsubsection{Affordability}

The machine is fabricated with readily available materials in the locality; thereby no need to settle for highly expensive imported materials that could raise the cost of production of the machine, hence make it unaffordable to farmers.

\subsubsection{Strength}

Before any construction work could be done on any machine, the behavior of stress action on the machine parts should depend on the load that machine is to carry and this is very essential. The strength solely depends on the materials used in the construction.

\subsubsection{Weight}

To determine the average weight of cobs was randomly picked and each of their weights was recorded and also cobs without seed (husks) was also weighed with weighing balance.

\subsubsection{Moisture content}

Grain water content should be reduced to $14 \%$ or less. It is therefore important to measure before shelling. Moisture increases the deformability of a grain resulting in damage. Hence, more energy is required to break a grain with adequate moisture content than the one with low moisture content.

\subsubsection{Strength of grain}

Grain hardness is an important property of grains and is of interest to both producers and consumers of grains. Cutting and cracking of grains provides breakage evaluation and consequently threshing efficiency.

\subsubsection{Shape and size}


These are closely related to physical factors of threshing efficiency in that they influence the shelling capacity and grain loss through sieves. A uniform size distribution enhances the effective uniform concave and separation by sieves.

\subsubsection{Density and specific gravity}

These factors are important in the separation or cleaning of grains from waste materials (chaff). It determines draft from a blower necessary for an effective cleaning process and grain loss.

\subsubsection{Variety of crop}

Crop variety affects the threshing efficiency in that the differences in grain length, grain size distribution along the ear, kernel and distance between grain rows might impair a uniform clearance in a sheller/thresher.

\subsection{Conceptual design}

Figures 1-2 shows the machine designed using AutoCAD 16.

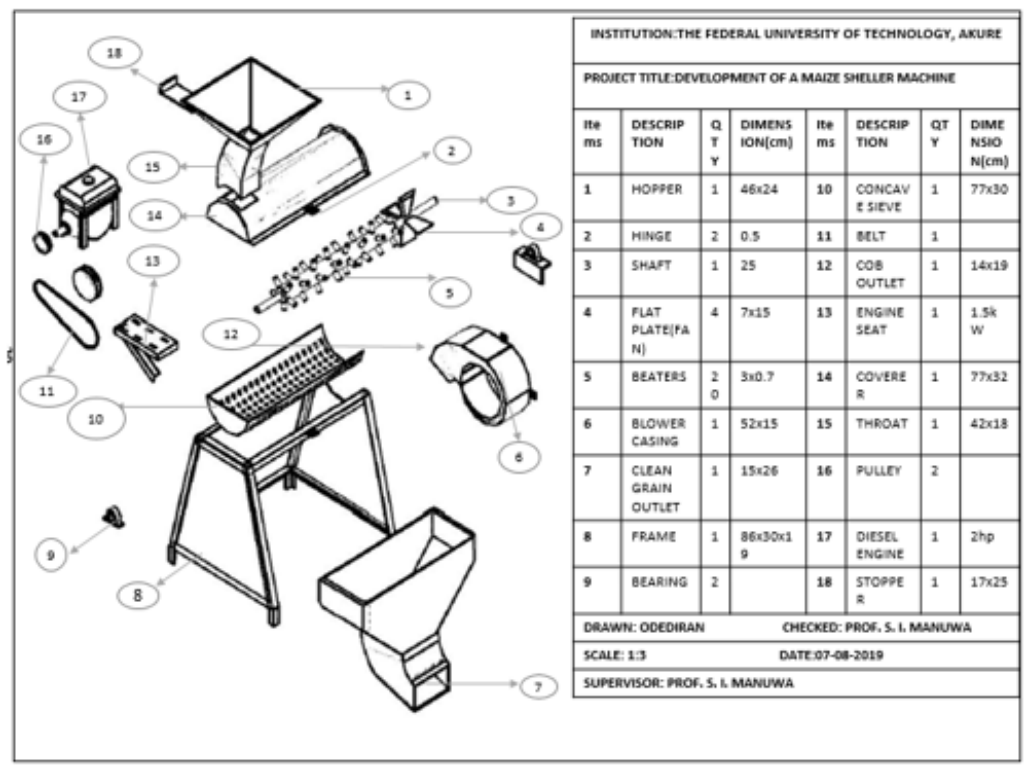

Fig. 1. Exploded view of motorized maize sheller.
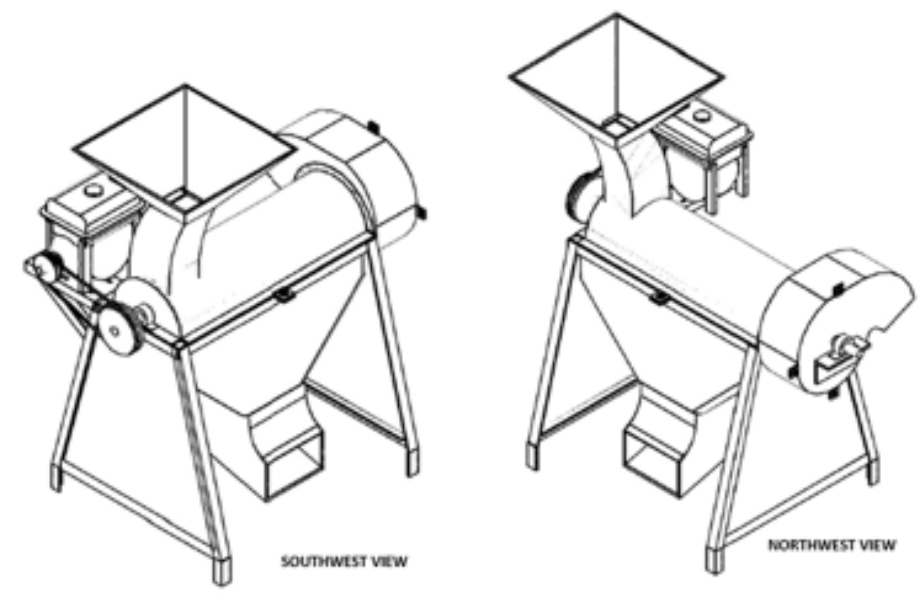

Fig. 2. Isometric view of motorized maize sheller. 


\subsubsection{Design analysis and calculations}

Machine component parts are subjected to external forces such as torque, friction, inertial forces, internal forces (as a result of temperature difference), pressure and both normal and shear stresses. Machine components should be able to withstand these forces so as not to fail. To design such a machine as to be capable of withstanding these forces, proper sizing and careful selection of materials for the various component parts is required.

The design analysis was carried out to evaluate the necessary design parameters, strength and size of materials. The design of various component parts of shelling unit is governed by physical properties, mechanical properties and engineering properties of maize. Others are the mechanism of rotating shaft over the concave at a specific clearance for the downward movement of the shelled grains.

The following are the design analysis and calculations for major component parts.

\subsubsection{Hopper}

Hopper design is founded upon a common criterion for it to function. The criterion is known as the "angle of repose". This type of hopper is a gravity discharge one and the recommended angle for agricultural materials is 80 or more and maize repose angle is 270 [10]. The hopper was designed to be a frustum, trapezoidal in shape and has the following dimensions that were chosen based on proportionality and aesthetics. The larger part is a square of $465 \mathrm{~mm}$ by $465 \mathrm{~mm}$ while the smaller part is also $108 \mathrm{~mm}$ by $108 \mathrm{~mm}$ with height of $235 \mathrm{~mm}$. To the vertical is 490 which is the measured angle of friction of maize. The minimum angle of inclination was calculated to be 850 . Hence, since 490 is greater than the repose angle of maize plus 80; the hopper will do the required job. The volumetric and gravimetric capacities of the hopper were determined. The volumetric capacity of the hopper, $\mathrm{Vh}$ was determined from the equation (1) by [11].

$$
V_{h}=\frac{h}{3} \cdot\left(A_{1}+A_{2}+\sqrt{A_{1} A_{2}}\right)
$$

where $A_{1}$ are area of the hopper top $=0.216 \mathrm{~m}^{2}, A_{2}$ are area of the hopper bottom $=0.0117 \mathrm{~m}^{2}, h$ are hopper height $=0.235 \mathrm{~m}$.

Therefore: $V_{h}=0.04749 \mathrm{~m}^{3}$.

The gravimetric capacity of the hopper, $\mathrm{G}_{\mathrm{h}}$ is related to the volumetric capacity of the hopper, $\mathrm{V}_{\mathrm{h}}$ using the equation (2).

$$
G_{h}=\rho V_{h}
$$

where $\rho$ are maize density $=415 \mathrm{~kg} / \mathrm{m}^{3}, \mathrm{~V}_{\mathrm{h}}$ are volume of hopper $=0.04749 \mathrm{~m}^{3}$.

$$
\mathrm{G}_{\mathrm{h}}=19.7 \mathrm{~kg}=193.26 \mathrm{~N}
$$

\subsubsection{Design of shaft}

It is a cylindrical solid rod for transmitting motion through a set of load carried on it. The shaft uses for the threshing is loaded by spikes, bearings, pulley, fan and belt tension. The design is based on fluctuating torque, bending moment and shearing force (Figure 3). For proper designing there is need to determine the shaft diameter, equation (3) was adopted:

$$
d^{3}=\frac{16}{\pi \delta s y}\left[\left(K_{b} M_{b}\right)^{2}+\left(K_{t} M_{t}\right)^{2}\right]^{\frac{1}{2}}
$$

where $\mathrm{d}$ are diameter of shaft $(\mathrm{mm}), \mathrm{Kb}$ are bending moment fatigue and shock, $\mathrm{Kt}$ are fatigue and combined factor for torsional moment, $\mathrm{Mb}$ are resultant bending moment $(\mathrm{Nm}), \mathrm{Mt}$ are resultant torsional moment $(\mathrm{Nm}), \delta$ sy are allowable bending stress $\left(\mathrm{MN} \mathrm{m}^{-2}\right), \pi$ are constant, 3.142. 


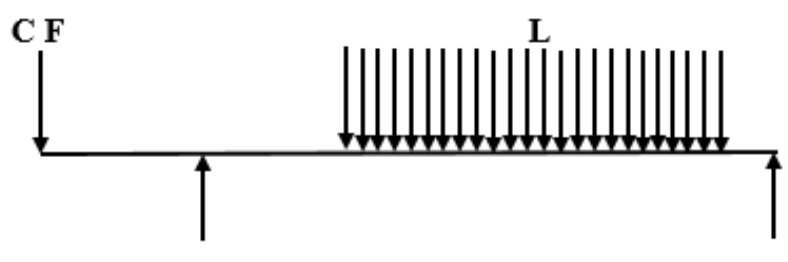

Rl

R2

Fig. 3. Representation of the forces: CF - centrifugal force due to flywheel load (N); L - force due to load exerted by cobs of maize and the spikes on the cylinder $(\mathrm{N})$; R1 and R2 - reactions from the two bearings $(\mathrm{N})$.

The uniformly distributed loads (Figure 4) are turned into a point load.

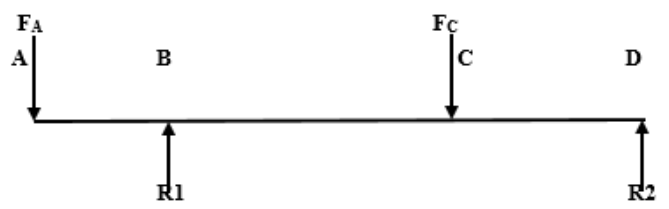

Fig. 4. Representation of loads.

Calculations:

$$
\begin{gathered}
\text { Weight of pulley }=2.3 \mathrm{~kg} \\
\mathrm{~F}_{\mathrm{A}}=2.3 \mathrm{~kg} \times 9.81=22.56 \mathrm{~N}
\end{gathered}
$$

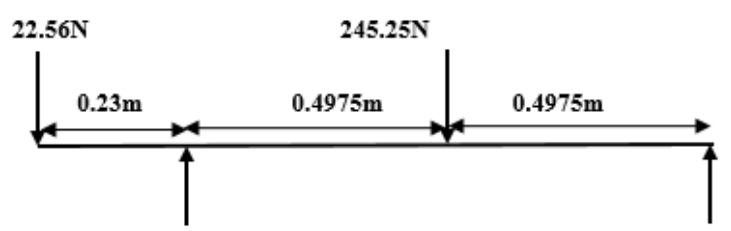

$\mathbf{R}_{1}$

Fig. 5. Reactions at point 1 and 2.

Taking moment about $\mathrm{R}_{1}$ (Figure 5):

$$
\begin{gathered}
-22.56 \mathrm{~N} \times 0.23 \mathrm{~m}-\mathrm{R}_{2} \times 0.995 \mathrm{~m}+245.25 \mathrm{~N} \times 0.4975 \mathrm{~m}=0 \\
-5.1888 \mathrm{Nm}-0.995 \mathrm{R}_{2}+122.011875 \mathrm{Nm}=0 \\
-0.995 \mathrm{R}_{2}+122.011875 \mathrm{Nm}-5.1888 \mathrm{Nm}=0 \\
-0.995 \mathrm{R}_{2}+116.823075=0 \\
-0.995 \mathrm{R}_{2}=-116.823075 \\
\mathrm{R}_{2}=\frac{-116.823075}{-0.995}=117.41 \mathrm{~N} \\
\mathrm{R}_{2}=117.41 \mathrm{~N} \\
\text { But, } \mathrm{R}_{1}+\mathrm{R}_{2}=22.56 \mathrm{~N}+245.25 \mathrm{~N} \\
\mathrm{R}_{1}+117.41 \mathrm{~N}=267.81 \mathrm{~N} \\
\mathrm{R}_{1}=267.81-117.41=\mathrm{R}_{1}=150.40 \mathrm{~N}
\end{gathered}
$$


Figure 6 present vertical loading diagram.

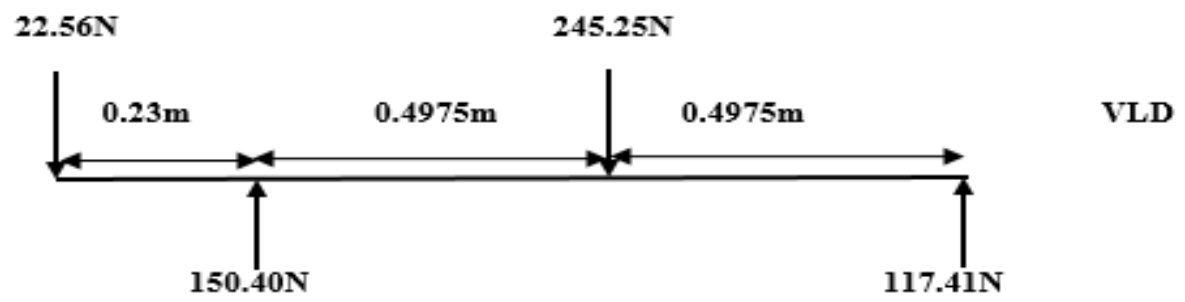

Fig. 6. Vertical loading diagram.

Figure 7 present vertical bending moment diagram.

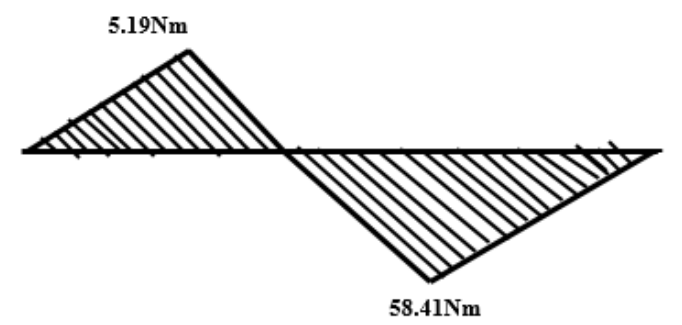

VBMD

Fig. 7. Vertical bending moment diagram.

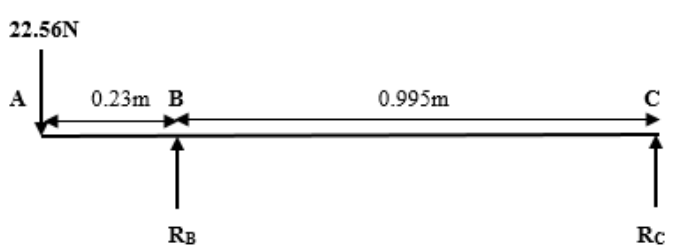

HLD

Fig. 8. Horizontal loading diagram.

From Figure 8, taking moment about $\mathrm{R}_{\mathrm{B}}$ :

$$
\begin{gathered}
0=22.56 \mathrm{~N} \times 0.23 \mathrm{~m}+\mathrm{R}_{\mathrm{C}} \times 0.995 \mathrm{~m} ; 0=5.1888+0.995 \mathrm{R}_{\mathrm{C}} \\
\mathrm{R}_{\mathrm{C}}=\frac{-5.1888}{0.995} \\
\mathrm{R}_{\mathrm{C}}=-5.21 \mathrm{~N}
\end{gathered}
$$$$
\mathrm{R}_{\mathrm{B}}+\mathrm{R}_{\mathrm{C}}=22.56 \mathrm{~N} ; \mathrm{R}_{\mathrm{B}}-5.21 \mathrm{~N}=22.56 \mathrm{~N} ; \mathrm{R}_{\mathrm{B}}=27.77 \mathrm{~N}
$$

Figures 9 and 10 present horizontal loading force diagram and horizontal bending moment diagram.

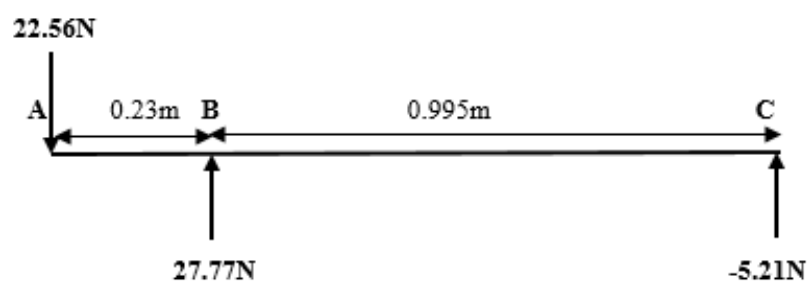

HLD

Fig. 9. Horizontal loading force diagram. 


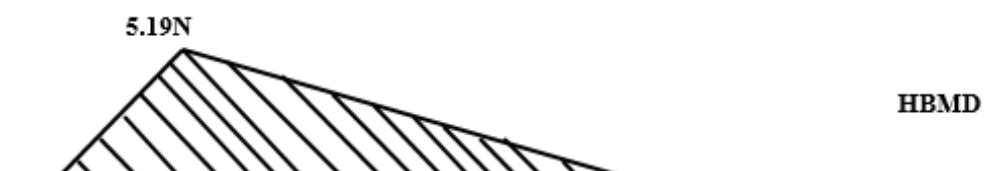

Fig. 10. Horizontal bending moment diagram.

At $\mathrm{A}, \mathrm{MBH}=0$

At $\mathrm{B}$, when $\mathrm{x}=0.23 \mathrm{~m}$

$\mathrm{MBH}=22.56 \times 0.23=5.1888=5.2 \mathrm{Nm}$

At $\mathrm{C}$, when $\mathrm{x}=1.225 \mathrm{~m}$

$\mathrm{MBH}=(22.56 \times 1.225)-(27.77 \times 0.995)=(27.636-26.775) \mathrm{Nm}$

$\mathrm{MBH}=0.861 \mathrm{Nm}$

Calculation of torsional moment:

$$
M t=\frac{p}{2 \pi N}
$$

where $\mathrm{Mt}$ are torsional moment $(\mathrm{Nm}), \mathrm{P}$ are power (watts), $\mathrm{N}$ are speed (rev/m).

$$
\mathrm{Mt}=\frac{1492}{2 x \Pi x \frac{2500}{60}}=\frac{1492}{261.8}=5.7 \mathrm{Nm}
$$

Calculation of maximum bending moment:

$$
M b=\sqrt{(M B V)^{2}-(M B H)^{2}}
$$

where $\mathrm{Mb}$ are maximum bending moment $(\mathrm{Nm}), \mathrm{MBV}$ are maximum vertical bending moment $(\mathrm{Nm}), \mathrm{MBH}$ are maximum horizontal bending moments $(\mathrm{Nm})$.

Therefore:

$$
\begin{gathered}
\mathrm{Mb}=\sqrt{(58.41)^{2}-(5.19)^{2}}=\sqrt{3411.7281-26.9361}=\sqrt{3384.792} \\
M b=58.18 \mathrm{Nm} .
\end{gathered}
$$

\subsubsection{Determination of shaft diameter}

The required diameter for a solid shaft is calculated using equation (3) [12].

Assumption:

$$
\begin{gathered}
\delta s=47 \times 10^{6} \mathrm{~N} / \mathrm{m} \\
\mathrm{Kt}=\mathrm{Kb}=1.5 \\
d^{3}=\frac{16}{\pi \delta s} \sqrt{(k b m b)^{2}+(k t m t)^{2}} \\
d^{3}=\frac{16}{\pi x 47 \times 10^{6}} \sqrt{(1.5 \times 58.18)^{2}+(1.5 \times 5.7)^{2}} \\
d^{3}=\frac{16}{\pi x 47 \times 10^{6}} \times 87.69
\end{gathered}
$$




$$
\begin{gathered}
d^{3}=\frac{1403.04}{\pi \times 47 \times 10^{6}} ; d^{3}=9.5 \times 10^{-6} \\
\mathrm{~d}=0.0212 \mathrm{~m}=21.2 \mathrm{~mm}
\end{gathered}
$$

Therefore, a $25 \mathrm{~mm}$ diameter shaft was selected.

\subsubsection{Design of shelling cylinder}

The number of spikes on the shelling cylinder is given by equation (6):

$$
N p=\frac{L_{c}}{S_{s r}} \times \frac{\pi d}{S_{s c}}
$$

where $\mathrm{Np}$ are shelling cylinder spikes, Lc are length of shelling cylinder $=750 \mathrm{~mm}$, Ssr are spike spacing on row $=90 \mathrm{~mm}$, Ssc are spike spacing on circle $=75 \mathrm{~mm}$, $\mathrm{d}$ is shelling cylinder diameter $=80 \mathrm{~mm}$.

Therefore $\mathrm{Np}=28$.

The total number of spikes on the shelling cylinder, $\mathrm{Np}=28$.

2.3.3.3. Determination of pulley or flywheel diameter of cylinder shaft

The diameter, $\mathrm{D}_{2}$ is given by the formula:

$$
D_{2}=\frac{N_{1} D_{1}}{N_{2}}
$$

where $\mathrm{N}_{1}$ are petrol engine motor speed $=1440 \mathrm{rpm}, \mathrm{D}_{1}$ are petrol engine pulley diameter $=80 \mathrm{~mm}, \mathrm{D}_{2}$ are diameter of driven pulley $=170 \mathrm{~mm}, \mathrm{~N}_{2}$ are shelling speed $=551 \mathrm{rpm}, N_{2}=\frac{N_{1} D_{1}}{D_{2}} ; \mathrm{N}_{2}=551 \mathrm{rpm}$.

Pulley diameter of blower shaft is kept constant to get the constant blowing speed as calculated using equation (7):

$$
N_{2}=\frac{N_{1} D_{1}}{D_{2}}
$$

2.3.3.4. Design of perforated concave screen

Total area of sieve:

$$
\mathrm{A}=\frac{2 \pi L}{2}=\pi \mathrm{rL}
$$

where $\mathrm{r}=112.5 \mathrm{~mm}, \mathrm{~L}=765 \mathrm{~mm}$ and $\mathrm{A}=270408.375 \mathrm{~mm}^{2}$ or $0.27 \mathrm{~m}^{2}$, Diameter of each hole $=15 \mathrm{~mm}$, area of each hole in a column (circular).

$$
\mathrm{A}=\pi \mathrm{rL}
$$

where $\mathrm{r}=7.5 \mathrm{~mm}$ and $\mathrm{A}=176.74 \mathrm{~mm}^{2}=1.767375 \times 10^{-4} \mathrm{~m}^{2}$

Total numbers of column $=20$

Total area of column $=20 \times 1.327 \times 10^{2}=2.65 \times 10^{3} \mathrm{~mm}^{2}$

Area of sieve under stress $=$ Total area of sieve - minus total area of column

Area of sieve under stress $=0.29-2.65 \times 10^{3}=307000 \mathrm{~mm}^{2}$ or $0.307 \mathrm{~m}^{2}$

Area of sieve $\mathrm{A}=307000 \mathrm{~mm}^{2}$ or $0.307 \mathrm{~m}^{2}$

$$
\mathrm{Fg}=0.319 \mathrm{~N}
$$


Stress on sieve $=1.039 \mathrm{~N} / \mathrm{m}^{2}$

\subsection{Materials selection}

\subsubsection{V-belt selection}

Belt depends on power to be transmitted at a required tension. The equation (9):

$$
\mathrm{P}=\left(\mathrm{T}_{1}-\mathrm{T}_{2}\right) \mathrm{V}
$$

where $P$ are the power in (watt), $T_{1}$ are the belt tension in tight side $(\mu), T_{2}$ are the belt tension in loose side $(\mu), V$ are the belt speed $(\mathrm{m} / \mathrm{s})=\frac{D \Pi N}{60}$, smaller pulley diameter are $\mathrm{D}(\mathrm{m}), \mathrm{N}$ are the belt speed $(\mathrm{m} / \mathrm{s})$

\subsubsection{Length of belt}

Here, the belt was considered as an open drive. This type of belt drive was employed when the two parallel shafts have to rotate. Belt length was obtained by using equation (10).

$$
L=\frac{2 C+\frac{\pi}{2} x\left(d_{1}+d_{2}\right)+\left(d_{1}+d_{2}\right)^{2}}{4 C}
$$

where $\mathrm{C}$ are length of central distance $(\mathrm{cm})$, putting the values of $d_{1}$ and $d_{2}$.

Therefore, $\mathrm{L}=1.732 \mathrm{~m}$

\subsubsection{Bearing selection and location}

The bearing is selected based on the load carrying capacity, life expectancy, and reliability. The shelling force is either by impact loading as seen in cylindrical beaters, or shearing force as seen in hand-threshing.

2.4.4. Power source and Horsepower requirement of motorized maize sheller

According to [13], the power delivered by a shaft is given by equation (11):

$$
\mathrm{P}=\mathrm{F} \times \mathrm{V}
$$

where $\mathrm{P}$ are power $\left(\mathrm{Nms}^{-1}\right), \mathrm{F}$ are force of shelling $(\mathrm{N}), \mathrm{V}$ are velocity $(\mathrm{m} / \mathrm{s})$.

Force required to thresh the maize is given by:

$$
\mathrm{F}=\mathrm{m} \omega^{2} r
$$

where $\mathrm{F}$ are force required to thresh maize, $\mathrm{m}$ is mass of threshing bars, $\omega$ are angular velocity of shaft, $\mathrm{r}$ is shaft radius.

The angular velocity $\omega$ is determined by the equation:

$$
\omega=\frac{2 N}{60}
$$

where $\mathrm{N}$ are threshing speed which is in revolutions per minute.

The power delivered is given by:

$$
\mathrm{P}=F \omega r \text { or } \mathrm{P}=F v
$$

Appropriate power of motor is determined or selected when the total power requirement for shelling is determined at an appropriate shelling speed. According to [14], the threshing speed that will give very low mechanical damage, but high threshing output is within the range of $300-650$ revolutions per minute.

The relationship between speed and torque of the prime mover is given by equation (14): 


$$
N_{1} T_{1}=N_{2} T_{2}
$$

The Torque developed is given by the relation:

$$
\mathrm{T}=\mathrm{F} \times \mathrm{r}
$$

\subsubsection{Power requirement}

As the torque transmitted by the shaft was known, the horsepower was calculated by using equation (17):

$$
H P=\frac{2 \pi N T}{4500} \quad \text { or } \quad P=\frac{2 \pi N T}{4500}[\mathrm{HP}]
$$

where $\mathrm{P}$ are power [HP], $\mathrm{N}$ are speed $(\mathrm{rpm})=956 \mathrm{rpm}, \mathrm{T}$ are torque $(\mathrm{kg} \mathrm{m})=1.18 \mathrm{~kg} \mathrm{~m}=1.5753 \mathrm{HP}(1.1747 \mathrm{~kW})$.

Therefore, actual horsepower required was 1.5753 HP. The calculated horsepower was 1.5753 HP; the motor efficiency and belt efficiency were calculated as $70 \%$ and $75 \%$, respectively. The recommended horsepower of machine was calculated by using the formula:

$$
\text { Required HP }=\frac{\text { actual hp }}{\text { motor efficiency } \times \text { belt efficiency }}
$$

The horsepower of machine was $2 \mathrm{HP}$.

\subsection{Description and working principle}

The machine is to be powered from the petrol engine mounted. The power supply moves through the belt connecting rotary pulleys. The same pulley gives rotation to the shelling cylinder located in the shelling chamber. Motion of the pulleys provide the discs velocity which pull and shell by friction and shearing action against the spikes of iron rod projected on the shelling drum. The empty cobs will pass out through the cobs outlet opening directed from the blower chamber and are thrown out by rotation of the blower blades as well as the air generated by the blower, while the dust and chaff are blown off by blower located near the shelling cylinder. The maize grains pass through the concave screen or sieve and then to the grain outlet chute from where clean maize grains are collected.

\section{RESULTS AND DISCUSSION}

\section{Hopper design}

The hopper of the sheller was fabricated in trapezoidal shape using mild steel sheet of $2 \mathrm{~mm}$ thickness. It is of dimension $465 \times 465 \mathrm{~mm}$ at the top and $108 \times 108 \mathrm{~mm}$ at the bottom. It designed as to aid conveyance, reduce the labour of constant feed and allows for continuous feeding.

\section{Transmission shaft}

This is a rod of $30 \mathrm{~mm}$ diameter, machined to $25 \mathrm{~mm}$ diameter and was used as shaft. The operations carried out was mainly facing and turning it was held between centers on the lathe machine.

\section{Shelling cylinder}

An I.S steel of $65 \mathrm{~mm} \times 750 \mathrm{~mm}$ rotated along the cylinder and separated grains from the cobs. However, cylinders with beaters are easy for manufacturing and are economical.

\section{Blower casing}

Steel plate of $2.5 \mathrm{~mm}$ thickness was used instead of wood and a thin sheet casing.

\section{Concave screen}

The concave steel plate of $6 \mathrm{~mm}$ thickness. The length of concave was $750 \mathrm{~mm}$ with slotted holes $10 \mathrm{~mm}$ diameter by considering average dimensions.

\section{Outer cover}

Sheet of diameter $18 \mathrm{~cm}$, incorporated with the hopper and was hinged and bolted to give protection to the cylinder and avoid grains spilling out. A hinge joint attached and bolt was to facilitate cleaning of inner cylinder. 


\section{Rotor Shaft}

Key components of the sheller was the rotor shaft; other parts such as flats of cylinders, blower and bearings were mounted. The standard size and length were selected considering the shaft design. The pulley was attached to give drive to shaft from motor.

\section{Outlet}

The outlet for separated grains was made at the bottom of the shelling cylinder. A metal sheet was used to collect grains without being shattered outside.

Frame

The whole sheller dimension was $77 \mathrm{~cm}$ x $42.5 \mathrm{~cm}$ x $128 \mathrm{~cm}$.

\section{Cob outlet}

The concave screen was inclined to $5-10^{0}$ to allow the shelled cobs to flow easily to the blower compartment from where it is blown through the outlet.

Power supply

The power supply to the machine is sourced from $2 \mathrm{hp}$ petrol engine. This is in conformation to the calculated required energy to run the machine. The rotational energy dissipated by the engine is transmitted through the belt and consequently to the shelling drum.

\subsection{Machine Testing}

The motorized maize sheller was tested for a variety for one (1) minutes and four trails were recorded. The highest throughput capacity of the sheller was $701.42 \mathrm{~kg} / \mathrm{h}$ at $2 \mathrm{~kg} / \mathrm{h}$ feed rate; the highest shelling rate obtained was 630.32 $\mathrm{kg} / \mathrm{h}$ with feed rate of $120 \mathrm{~kg} / \mathrm{h}$ and it was observed that the highest machine efficiency obtained was $94.98 \%$.

\section{CONCLUSIONS}

Since most maize shelling and threshing are done manually, this has proven to be stressful and not effective, therefore there is a need to improve the technology used in shelling maize. A motorized maize sheller machine has been designed and fabricated with locally available materials. The machine was powered with a diesel engine with design considerations to make the machine affordable and efficient. The machine was tested and found to satisfactory to shell maize with throughput capacity of $701.42 \mathrm{~kg} / \mathrm{h}$, shelling rate of $630.32 \mathrm{~kg} / \mathrm{h}$ and machine efficiency of $94.98 \%$. The machine designed if adopted by fabricators and commercial farmers can improve productivity and reduce post-harvest losses.

\section{REFERENCES}

[1] Kogbe, J.O.S., Adediran, J.A., Influence of N, P and K application on yield of maize in Savannah Zone of Nigeria, African Journal of Biotechnology, vol. 2, no.10, 2003, p. 345-349.

[2] Pimentel, D., Patzek, T.W., Ethanol production using corn, switch grass, and wood; biodiesel production using soybean and sunflower, Natural Resources Research, vol.14, no. 1, 2005, p. 65-76.

[3] Mahatale, Y.V., Pathak, V.P., Physiological evaluation of different manually operated maize shelling methods, International Journal of Applied Agricultural Research, 2012, vol. 3, no. 7, p. 203-207.

[4] IITA, International Institute for Tropical Agriculture. Growing in Nigeria. Commercial Crop Production Guide Series. Information and Communication Support for Agricultural Growth in Nigeria, USAID, 2012, p. 1-8.

[5] Cadini, P., Angelucci, F., Analysis of incentive and disincentive for maize in Nigeria. Monitoring African Food and Agricultural Policies, Technical Report Series MAFAP/FAO Rome, 2013, p. 41.

[6] Iken, J.E., Amusa, N.A., Maize research and production in Nigeria, African Journal of Biotechnology, vol. 6, 2004, p. 302-307.

[7] Obi, I.U., Maize: its agronomy, diseases, pests and food values, Optimal Computer Solutions Limited, Enugu, 1991, p. 208-210.

[8] Nkakini, S.O., Ayotamuno, M.J., Maeba, G.P.D., Ogaji, S.O.T., Probert, S.D., Manually-powered continuous flow maize sheller, Applied Energy, vol. 84, 2007, p. 1175-1186. 
[9] Singh, S.P., Pratap, S., Design and development of hand operated maize dehusker-sheller for farm women, Agricultural Mechanization in Asia, Africa, and Latin America, vol. 43, no.1, 2012, p. 152-154.

[10] Aremu, D.O., Adewumi, I.O., Ijadunola, J.A., Design, fabrication and performance evaluation of a motorized maize shelling machine, Journal of Biology, Agriculture and Healthcare, vol.5, no.5, 2010, p. 154-164.

[11] Eric, O., Franklin, D.J., Holbrook, L.H., Machinery handbook, 21st edition, Industrial Press Inc., New York. 1982.

[12] Hall, A.S., Hollowenko, A.R., Laugh, H.G., Theory and problems of machine design, Schaum's Outline Series, McGraw - Hill International Book Company, Singapore, 1983, p. 113 - 130.

[13] Shigley, J.E, .Mechanical engineering design, McGraw-Hill, New York, USA, 1986.

[14] Fashina, A.B., Abdulahi, H., Performance evaluation of a locally developed direct-power-take off driven maize thresher, Journal of Agricultural Technology, vol. 2, no.1, 1994, p. 1-5. 